\title{
On the Problem of Formalism in Economics
}

\author{
Geoffrey M. Hodgson
}

3 February 2005

An earlier version was published in the Post-Autistic Economics Review, Issue 28, 25 October 2004

This version was published in:

Economics in the Shadows of Darwin and Marx: Essays on Institutional and Evolutionary Themes, Edward Elgar, Cheltenham, 2006, ch. 7.

'O Probleme formalisma v economicheskoi teorii' (in Russian), Voprosy Economiki, 2006, no. 3, pp. 112-124.

The Business School, University of Hertfordshire, De Havilland Campus, Hatfield, Hertfordshire AL10 9AB, UK http://www.herts.ac.uk/business http://www.geoffrey-hodgson.ws g.m.hodgson@herts.ac.uk 


\title{
On the Problem of Formalism in Economics
}

\author{
Geoffrey M. Hodgson
}

\section{Modern Economics is Sick}

In his Reorienting Economics, Tony Lawson cites this magnificently appropriate quotation by Mark Blaug (1997, p. 3):

Modern economics is sick. Economics has increasingly become an intellectual game played for its own sake and not for its practical consequences for understanding the economic world. Economists have converted the subject into a sort of social mathematics in which analytical rigour is everything and practical relevance is nothing.

I believe that on this issue, Lawson, Blaug and I are in agreement: the victory of technique over substance is a chronic problem within modern economics. Although the victory of formalism can be dated to the 1950s (Blaug 1999, 2003), by the 1980s the problem had become much more serious. Because mathematics has swamped the curricula in leading universities and graduate schools, student economists are neither encouraged nor equipped to analyze real world economies and institutions. Arjo Klamer and David Colander (1990, p. 18) reported a survey which showed that only 3 per cent of graduate students on top US economics programmes perceived 'having a thorough knowledge of the economy' to be 'very important' for professional success, while 65 per cent thought that 'being smart in the sense of problem-solving' is what matters, and 57 per cent believed that 'excellence in mathematics' was very important.

In 1988 the American Economic Association set up a Commission on the state of graduate education in economics in the US. In a crushing indictment, the Commission expressed its fear that 'graduate programs may be turning out a generation with too many idiot savants skilled in technique but innocent of real economic issues' (Krueger et al, 1991, pp. 1044-5). Alan Blinder (1990, p. 445), a member of the Commission, commented:

Both students and faculty find economics obsessed with technique over substance . . . the many macro and micro theory exams the Commission examined . . . tested mathematical puzzle-solving ability, not substantive knowledge about economics . . . Only 14 percent of the students report that their core courses put substantial emphasis on 'applying economic theory to real-world problems.'

Alarm bells concerning technique displacing substance in economics have been sounding for many years (Ward, 1972). However, although mainstream economics has made some significant theoretical advances in the 1990s, including an increasing adoption of institutional and evolutionary themes, the situation concerning formalism has not got any better.

Perhaps the most serious emerging problem is that the graduate students of the 1980s and 1990s, who are skilled in technique but who have an impoverished understanding of economic principles and their history, are now beginning to achieve positions of seniority and 
influence in the university departments, associations and journals of the economics profession. Their growing power and influence will ensure that formalism further consolidates its overwhelming hegemony, to the detriment of wider-ranging conceptual and methodological enquiry. This problem is particularly serious in Britain and America, where formalism has achieved its earliest and most complete victory. But the process is delayed rather than absent elsewhere.

Both Blaug and Lawson face the problem of formalism head-on. But, as I shall elaborate below, their evaluations differ. Blaug complains that formalism has been associated with a detachment of economics from substantial and practical issues. Lawson's $(1997,2003)$ attack is more extensive and radical. He develops at length a methodological critique of what he calls 'deductivism' and identifies this as the root of the formalist malady. One of my main purposes here is to examine some prominent aspects of Lawson's critique of formalism. I shall argue that his stance is too limiting, with the expected outcome that mathematical and econometric tools will be illegitimate except under 'seemingly rare' (Lawson, 2003, p. 21) conditions.

\section{Tony Lawson's Critique of Formalism}

Lawson affirms that the systems addressed by the social sciences are open, in that they are subject to multiple extrinsic and intrinsic disturbances. This makes the task of prediction either difficult or impossible. For Lawson (1997, p. 288), 'event prediction is usually infeasible' and 'in any case not required for a successful science of economics'.

Lawson (1997, pp. 16-17) argues that 'deductivism' presumes 'event regularities' or 'constant conjunctions of events or states of affairs' with regularities of the form 'whenever event $\mathrm{x}$ then event $\mathrm{y}$ '. Philosophically, this is a rather atypical definition of deductivism, because it refers to empirical regularities concerning events rather than logical deductions concerning propositions. He seems to suggest that logical or mathematical constructions, if they are to be of relevance or use, must be some kind of map of reality at the level of events. For example, Lawson (2003, p. 22) writes of the importance of a “"fit” with reality'.

From this stance, his critique of the use of formalism in economics readily follows. Social reality is an open system, generally lacking in 'constant conjunctions of events'. By contrast, in either a strict or a stochastic sense, formal models generate regularities in the form: if $\mathrm{x}$ then y. Such event regularities are highly limited in the social realm. Accordingly, there is a general mismatch between formal models and reality. If economics is to progress, then formal modelling must be limited those cases where such regularities pertain, and these appear to be rather rare.

In the absence of formal models, what does the theorist do? Lawson realizes that no theory (formal or discursive) can proceed without some degree of abstraction: it is impossible to consider all elements and interactions at once. Indeed, he develops his methodological notion of abstraction at length. But here he faces a difficulty. If abstraction is necessary, and it involves the limitation of the sphere of consideration and the exclusion of additional relations or disturbing forces, then doesn't this too imply the assumption of a closed system? Stephen Nash (2004) has recently argued in the affirmative, suggesting that Lawson too must assume conditions or forms of closure. To some extent, however, Lawson (1997, p. 236) anticipates this objection. He proposes a distinction between 'abstraction' and 'isolation' in the following terms: 
When we focus upon varying productivity performances here, conditions of work there, rising or falling unemployment rates, and so on, we do not suppose that these features we choose to emphasise exist in isolation, even as a temporary, heuristic, measure. To do so is to assume a totally different world from the one in which we live, and one that has no bearing upon it. ... In short, there is literally a world of difference between leaving something (temporarily) out of focus and treating it as though it does not exist. The achieving of an abstraction and treating something as though it existed in isolation are not the same thing at all.

He uses this distinction to protect his argument against the objection that his method of abstraction also implies the assumption of closure; he argues that abstraction does not imply closure but isolation does. With some important nuances and qualifications, Lawson (1997, pp. 131-3) associates the notion of isolation with the work of Uskali Mäki $(1992,1994)$ and contrasts isolation with his own concept of abstraction. However, I shall argue later below that the distinction is, at least in prominent practical instances, difficult to sustain.

Lawson takes a relatively extreme position in his attitude to formalism in economics, even among critics of mainstream economics, and even among the school of 'critical realists' to which he belongs. For example, critical realists such as Paul Downward (2000, 2003) have defended a more frequent use of some econometric techniques. Lawson points to very few concrete instances where econometrics has been appropriately deployed; Downward points to several. And the critical realist Erik Olin Wright (1994, pp, 183-9) has strongly supported the use of 'explicit abstract models, sometimes highly formalized as in game theory' and other 'rational choice models'. Lawson takes an extreme position, even within critical realism. An extreme position such as Lawson's is not necessarily inappropriate or wrong by virtue of its extremism, but it does invite repeated criticism.

Perhaps as a consequence, in Lawson's later writing there has been a slight shift of tone and emphasis, if not substance as well. For example, Lawson (1999, pp. 7-8) proposes that from the fact that 'the world is open and structured, it does not follow' that economists 'ought thereby not to engage at all in formalistic methods such as econometrics.' He continues:

The possibility of successes with the latter requires local closures. ... Critical realism thus cannot and does not rule out a priori their limited occurrence. Rather, critical realism adopts an essentially ex posteriori orientation ... the opponent is the advocate of any form of a priori dogma.

With some amendments, Lawson (2003, pp. xix, 27, 178-9) repeats a similar argument in several places in his latest book. Again and again he insists that he is not against the use of econometrics or models in principle, but that they are of highly limited use given the closure conditions upon which they depend. He writes that 'a blanket rejection of econometrics, or indeed of any other method, is not a stance that is, or could be, sponsored in critical realism.' What is opposed is not econometrics but 'the reduction of economics to formalistic analysis.' But he then goes on to say that the 'application of formalistic methods requires certain (closure) conditions constituting special configurations of social reality that (unsurprisingly from the perspective sustained) have turned out to be rather rare.' In a recent essay, Lawson (2004) again repeats his insistence that he is not 'anti-mathematics'. But his expectation remains that the conditions for its effective and proper use would be rare.

In these passages at least two features are emphasized. The first is a strong, sincere and repeated claim of anti-dogmatism concerning whether or not mathematics can or should be used. But he lays down criteria for its use, including the requirement of (approximated) local closure. As a result of these criteria, the specific measure of his own anti-dogmatism, in 
practice rather than in intention, is how far he would admit that open systems might appear (or be approximated) in reality. Lawson argues that his critical realist perspective suggests at the outset that they are 'limited' or even 'rather rare'. Accordingly, the ontological arguments in Lawson's critical realism lead him right away to expect that the possibilities for formalism are highly restricted. This sets limits on his anti-dogmatist stance, despite his pronounced antidogmatist intentions. Although Lawson imposes no absolute normative ban on the use of mathematics, his arguments limit its legitimate use to 'rare' circumstances only.

Generally, one can also ask if an all-pervasive, anti-dogmatist stance were possible. Some prior 'dogmatic' presuppositions are necessary for any engagement with the world. We assume that our car will start and the sun will rise in the morning. We assume that the face we recognise is the face of the same person with which it was associated yesterday. We assume that the meanings of words have not changed overnight. The removal of all dogma would mean a disabling nihilism of universal scepticism. In such circumstances, no observation could be completed and no theory could be established. Human activity would become paralyzed if we ceased to believe in the essential dogma that most of the natural regularities and social institutions of today will survive until tomorrow. We often admire anti-dogmatism as a commendable personality trait, but modern philosophy of science upholds that some considerable degree of dogmatism is unavoidable. As Charles Sanders Peirce (1934, p. 156) put it long ago, contrary to René Descartes we 'cannot begin from complete doubt. We must begin with all the prejudices which we actually have'.

The second feature of Lawson's argument above is the proclamation of 'an essentially ex posteriori orientation', although what precisely is meant by this is insufficiently clear. Critical realists rightly emphasize the importance and priority of ontological commitments. Consider fundamental ontological commitments such as ‘ubiquity determinism' (Bhaskar, 1975, pp. 701), which means that every event is deemed to have a cause. We have known at least since the days of David Hume that it is impossible to deduce causes a posteriori from our experience of events. It is in the very nature of such primary ontological commitments that they are neither based on nor deduced from evidence or experience. One of the crucial aspects of the philosophical assault on positivism in the middle of the twentieth century was the reaffirmation of the importance of such prior ontological commitments, which cannot be established by appeal to evidence or experience alone (Quine, 1951; Caldwell, 1982). So one is left wondering what 'an essentially ex posteriori orientation' means, and how it can be reconciled with an insistence on the primacy of ontology.

Again I detect a slight post-1997 shift of tone and emphasis when Lawson (2003, pp. 20-1) openly discusses the possibility that econometrics might be of use in some instances:

Clive Granger has argued convincingly that it is possible to use econometrics to provide relatively successful short-run forecasts of phenomena such as electricity loads and peaks in regions wherein one factor, temperature, or more specifically the extreme cold, dominates behaviour. ... The point remains, however, that the sorts of conditions in question appear a posteriori not to be typical of the social realm. Rather, as I say, social reality is found to be a quintessentially open, structured, dynamic and highly internallyrelated system, amongst other things, whilst the conditions for achieving a local closure are seemingly rare.

This is the only example I can find where Lawson has pointed to a specific piece of econometric analysis and acknowledged its legitimacy. Note, however, the strictness of the key condition involved. According to this passage, for econometrics to be applicable, 'local closure’ must be actually achieved, not merely approximated. However, it is clearly the case $a$ 
posteriori that electricity consumption (even in cold regions) is a feature of an open rather than a closed system. For instance, electricity consumption is generally affected by its price. Such prices are heavily influenced by global market conditions. Global markets are far from being closed systems. Granger did not provide an example which establishes local closure. Granger's (2004) defence of econometrics applies to a broader class of phenomena. By the logic of his own argument, Lawson should have deemed econometrics to be also inapplicable to this electricity generation situation described by Granger. Lawson's single claimed example of the legitimate use of econometrics turns out to be illicit according to his own key criterion.

Indeed, if we require that formal models can only be applied in contexts where local closure is actually achieved, then this would mean that such models were inappropriate in other sciences and disciplines, such as biology, physics or engineering. Generally, in multiple contexts, in both the natural and social world, such closures are absent, as Roy Bhaskar (1975) as well as Lawson himself have emphasized. If formal models require strict local closure, then formal models are never appropriate. But this would overlook the achievement of mathematical models in some sciences. It may be suggested that local closure is sometimes approximated in physics, and because of this some formal models can be of use. But it must be added that models generated through experiments in situations where local closure is approximated have often been demonstrated to be of considerable value in much wider applications. Furthermore, models and simulations have also been used with some success in biology and evolutionary anthropology, which face a high degree of complexity and openness (Murray, 1989; Boyd and Richerson, 1985).

At least in recent seminar presentations, Lawson has amended his position still further, by proposing that econometrics might apply when local closure is 'approximated in reality'. This formulation contrasts with that in his two $(1997,2003)$ books, which generally insist that local closure conditions must actually apply for formalism to be viable. From his amended standpoint, admitting a degree of approximation to closure, it would be possible to admit the Granger example as a case of the legitimate application of econometric techniques. The general problem for Lawson in applying this revised criterion more widely is that the degree of acceptable approximation is left unspecified. In general, once the insistence on the actual achievement of local closure is removed, and approximations to closure are admitted, then the door to econometrics is unlocked and opened.

\section{Some Key Problems and Omissions in Tony Lawson's Critique}

Much of Lawson's discussion of formalism concerns econometrics. He gives insufficient attention to other applications of mathematical techniques, which serve primary purposes other than the prediction or explanation of measurable variables. Such additional applications of formalism include (a) heuristics and (b) internal critiques. I shall address each of these in turn.

The purpose of a heuristic is to identify possible causal mechanisms that form part of a more complex and inevitably open system. Heuristics can be useful without necessarily making adequate predictions or closely matching existing data. Their purpose is to establish a plausible segment of a causal story, without necessarily giving an adequate or complete explanation of the phenomena to which they relate.

An example of a formal heuristic that has been persuasive in economics is the ethnic segregation model constructed by Thomas Schelling (1969). Using a very simple model of housing location, Schelling showed that ethnic segregation can result even from very small 
feedback effects. Even if people only have a very slight preference for their own ethnic group, this can be enough to cause migration out of mixed ethnic areas, with the end result of segregated ethnic ghettos. The model is extremely simple, and hardly realistic in its detailed assumptions. However, making the model more complicated and 'realistic' would be beyond the point, partly because it is obvious that similar outcomes could result from a more complicated model. Instead, the Schelling model points to a credible mechanism that shows that ethnic segregation does not necessarily depend upon the actions of bigoted racists. Such racists exist in the real world, so their inclusion in the model would make it more realistic. But this would defeat the object of the model, which is to show that segregation might result even without them. The model abstracts from the more forceful versions of racism that we find in the real world to establish this key point. In this case, the power of the model is helped by its unrealisticness. The power of the model lies in its capacity to abstract a plausible bit hitherto neglected causal mechanism.

In a very useful discussion of such 'credible worlds', Robert Sugden (2000) asks probing questions concerning the role and 'realisticness' of this and other heuristic models in economics. These heuristic models have the paradoxical claim that they are literally unrealistic yet they seem to illuminate important aspects of reality. Using the Schelling model alongside George Akerlof's (1970) famous article on the 'market for lemons', which again claims to establish meaningful propositions about the world on the basis on an admittedly unrealistic model, Sugden (p. 28) describes these models as 'credible counterfactual worlds' that give 'some warrant for making inductive inferences from model to the real world.'

In no case can the construction of a heuristic or counterfactual model clinch the argument concerning the causal mechanisms that actually exist in the real world. However, what they sometimes do show - as in the case of the Schelling model - is that outcomes might not necessarily result from the causal factors that may be presumed at first sight. To complete the argument, further theoretical development and empirical enquiry are always required.

I have suggested above that heuristics are appropriate if they successfully abstract an important causal mechanism in reality. Accordingly, heuristics relate to the very process of abstraction that Lawson himself highlights. But Lawson suggests that heuristics are isolations rather than abstractions. So here I must return to Lawson's (1997, p. 236) attempted distinction between isolation and abstraction, as quoted above. According to him, the key difference is 'between leaving something (temporarily) out of focus and treating it as though it does not exist'. Again take the Schelling model as an example. Schelling himself accepts that bigoted racists exist, yet he leaves them out of his model. The purpose of the model is not to excuse or deny racism, but the more severe forms of racism are deliberately removed. Nevertheless, the model is extremely and worryingly persuasive.

No-one to my knowledge, including Schelling himself, has suggested that such as model is a complete or adequate causal representation of the processes underlying the emergence of ethnic segregation in reality. The model is simply a heuristic step along the road towards that more complete end. More generally, no sensible mainstream economist would deny that the world is open, and no adequate presentation of a formal model would omit to mention that other (omitted) causal mechanisms exist.

Ultimately, Lawson's attempted distinction between abstraction and isolation hinges on the precise meaning of notions such as 'treating [that which is left out of the picture] as though it does not exist' and the implied distinction between a 'temporary heuristic' and 'leaving something temporarily out of focus'. Yet Lawson is insufficiently precise here. If I 'focus' on the workings of a national economy (perhaps without building a mathematical model) and 
ignore its trade with other nations, then in what sense might this qualify as a temporary account, rather than a presumption that such exports and imports do not exist? Surely, some verbal statement would be required, acknowledging the existence of international trade, explaining its omission from the current discussion, and suggesting that further work must be done to incorporate it into the analysis. But this is also the kind of necessary qualification that we should expect from the best presentations of heuristic models. On the other hand, it would be impossible to mention all the things that we have left out of the account. In this sense all theory is 'temporary'. But do such unmentioned omissions amount to treating some causal linkages as though they do not exist? If this were the cases, then every theory, including nonformal, discursive theory, by Lawson's criteria is a failure. Once we try to apply Lawson's criteria, then their insufficiency and vagueness become apparent, and his attempted distinction between abstraction and isolation is revealed as highly problematic.

A crucial point here is that in economics we should not and cannot judge models in isolation. Lawson treats any model as if it were alone an intrinsic claim to be a partial map of the world. Yet the meaning of any heuristic model depends upon an interpretive framework that is not contained in the formalities of the model itself. If heuristic models are suitably hedged and qualified, in the manner suggested above, then these qualifications form part of the interpretative apparatus for the model. If heuristic models are treated within an adequate interpretative context, then such heuristic packages can successfully defend themselves against the charge that they treat other aspects of reality as though they do not exist.

By contrast, Lawson himself isolates formal models from their interpretative contexts, treating these as if they do not or need not exist, and denies the validity of even 'temporary' heuristic models per se. The strictures of appropriate contextualization that Lawson rightly requires of discursive theory should apply to his treatment of formal models as well.

Bringing the interpretative framework of a heuristic model into the picture is highly important in appraising the problem of excessive or misplaced formalism in economics. An alternative diagnosis emerges, in which the malady is not the use of formalism as such but the inadequacy and underdevelopment of the interpretative context in which they are placed. Technique can take priority over substance as a result of the relative neglect of interpretative context. An adequate interpretative framework would depend on the discussion of the genesis, meaning and methodological significance of key concepts that are involved in the model or its interpretation. This is never a small task, and if done properly it will be at least as weighty as the formal technique of the model itself. Yet in modern economics such interpretative and conceptual matters are often marginalized and underdeveloped. I contend that this is one of the main problems with formalism in economics today.

While Lawson implicitly treats formal models as if they were claims to map the world, his explicit metaphor is more frequently of the model as a tool. For example, Lawson (2003, p. 12) notes the ontological mismatch between formal models and reality and suggests that this is grounds to question their use: 'Few people ... would attempt to use a comb to write a letter ... or a drill to clean a window.' This argument is not as illuminating as it may seem at first sight. Of course, we would use a pen to write a letter and a clean cloth to clean a window. Yet the ontology of pens is very different from that of letters, and likewise there is a big ontological difference between clean cloths and dirty windows. So there is nothing in this appropriateness-of-tools argument that rules out, for instance, using closed models to help understand an open reality.

I now turn to the second use of formalism that is neglected by Lawson: that of an internal critique. Generally, the impact of an effective internal critique is negative rather than positive; 
it shows the limits of an existing theory rather than building a new one. It is nevertheless important. Consider the example of the critique of mainstream capital theory by Piero Sraffa (1960) and others. By developing a model with disaggregated rather than aggregated physical capital, Sraffa showed that the measure of capital could not be independent of profits, wages or prices. Consequently, any attempt to explain the latter by means of an aggregated capital variable must assume that which it has to explain. The validity of this argument was later accepted by Paul Samuelson and others (Harcourt, 1972). It meant that several of the models and arguments used in the mainstream theory of capital and distribution were either invalid or dependent on highly restrictive assumptions.

A demonstration that a widely adopted approach depends on restrictive or even implausible assumptions is a key feature of many of the successful and significant internal critiques that we find in economics. Other examples include works by Rolf Mantel (1974) and Robert Rowthorn (1999). Mantel and several other theorists showed that even with the assumption of individual utility-maximization, the excess demand functions in an exchange economy can take almost any form, and there is thus no basis in standard general equilibrium theory for the assumption that they are generally downward sloping. Their work proved very influential in bringing the microfoundations project in general equilibrium theory to an end (Rizvi, 1994). Rowthorn showed that prominent models used by governments in macroeconomic policymaking are based on highly restrictive and unwarranted assumptions.

Such critiques do not themselves provide new theories, although they may suggest some appropriate measures and establish some relevant pointers. By their nature, internal critiques are not claims to map the real world. Instead, they are attempts to show that that other theories are inadequate or overly restrictive in regard to the kind of world to which they relate. I have not come across an adequate discussion of the role of internal critiques in Lawson's work, despite their prevalence the Cambridge tradition of economics that used to be well established in his university department.

Significantly, neither heuristics nor internal critiques are attempts to map the world with a model. Accordingly, insofar as they are of some scientific use, severe doubt is cast on Lawson's central argument that the adoption of a particular model involves explicit or implicit assumptions about the ontology of the social world. For him, if an assumption does not occur in reality, then it is illegitimate in theory - a proposition which would invalidate much theory in most disciplines. By contrast, it would seem that some models are of use, even if there is a significant misfit with reality. If so, then Lawson’s main argument falls.

\section{Conclusion}

In regard to formalism, many economists propose the extreme view that it is the principal and necessary means by which economics becomes rigorous and scientific, and thus the dominance of formalism is a positive sign of success. Lawson takes a position near the other extreme. He argues that formalism is justified in 'rare' circumstances only, where local closure exists or is approximated. I propose that both attitudes to formalism are flawed, partly because they both downplay its necessary interface with interpretative structures.

Yet while Lawson and the mainstream are at odds, there are some shared presuppositions. Many mainstream economists assume that their models are sufficient to represent the world, neglecting the interpretative discourses required to make such a claim meaningful. Lawson too believes that the adoption of a formal model intrinsically upholds some substantial claims concerning the nature of reality. I believe that both positions are false. 
If modern economics is sick, then what is the nature of the sickness? A good answer to this question is required to help us find an appropriate remedy. Lawson's medicine is to require the application of formalism only when local closure is achieved or perhaps approximated. However this remedy virtually ends up as an inversion of the disease itself, and I have argued that it is based on a faulty diagnosis.

Especially in his recent writing, Lawson has insisted that he is not against formalism as such, and he has no dogmatic prescription concerning its use. However, I am aware of only one example of a piece of econometrics which Lawson has deemed as legitimate, and even here to admit it he has to fudge the criterion of strict closure declared in his 2003 book. More recently (but until now only verbally as far as I am aware), he has relaxed this criterion to allow econometrics to be used when closure is approximated, rather than actually achieved.

The consequent challenge for Lawson is to be more specific about the degree of approximation and to point to still further examples of the legitimate use of mathematical models in economics. Until this is done, Lawson remains in the extreme position of admitting as legitimate only one specific case, among hundreds of thousands of examples that are available to us.

Middle ground solutions are not intrinsically warranted simply because they are middle ground. But part of the tragedy of modern economics is that they have so far received limited attention and consideration, with notable exceptions such as a recent article by Victoria Chick and Sheila Dow (2001).

I suggest that the problem with formalism is not the general inappropriateness of formalism itself, but it is the problem identified by Blaug in the quotation near the beginning of this article. Blaug sees the kind of formalism in modern economics as 'an intellectual game played for its own sake' rather than for its use in explaining and engaging with the real economic world. Blaug complains that in modern economics 'analytical rigour is everything and practical relevance is nothing'. Again the solution here is not necessarily to confine formalism to the very rare conditions of actual or approximated closure, but to ensure that concerns for practical relevance come to the fore. Formal techniques should be the servants rather than the masters of scientific enquiry.

It is also worth bearing in mind that there is an example of a social science in which formal methods and models have hitherto been put to little use, apart from statistics. Yet this discipline is widely acknowledged to be in a state of severe disorder, especially concerning its core presuppositions, its self-identity and boundaries, and its relations with other disciplines, particularly economics and biology. This afflicted social science is sociology. The persistence of its acute scientific maladies alongside its relatively infrequent use of formalism indicates that additional problems exist within the social sciences today. These include the postmodernist affirmation that one theory is as good as another, the frequent choice of a theory on ideological rather than scientific grounds, and an occasional self-inflicted blindness concerning the biological aspect of human nature and its significance for the study of human society.

Despite our differences of view, I wish to emphasize that both Lawson and myself, and others here cited including Blaug, Chick, Dow and Mäki, adopt a realist philosophical perspective. Realism acknowledges that a world exists beyond our perceptions. Realists uphold that, to be adequate, sciences including economics should not be self-contained logical games but attempts to address and understand aspects of the real world. Accordingly, there is no room for a philosophy of science in which 'anything goes'. There is a shared realist imperative: to understand the real world. 
However, I argue here that there is a place for mathematics in economics, even when conditions of closure are absent or fail to be approximated. I have emphasized the greater importance of the interpretative structure within which the theory is placed. The pressing agenda issue for further discussion and enquiry in this area is to explore the inadequately explored middle ground between the unacceptable extremes of unreflecting worship and (at least expectational) denial of formal models and methods. 


\section{Acknowledgement}

The author wishes to thank Mark Blaug, Victoria Chick, Sheila Dow and Tony Lawson for very helpful comments on earlier versions of this essay.

\section{References}

Akerlof, George A. (1970) 'The Market for “Lemons”: Quality Uncertainty and the Market Mechanism', Quarterly Journal of Economics, 84(3), August, pp. 488-500.

Bhaskar, Roy (1975) A Realist Theory of Science, $1^{\text {st }}$ edn. (Leeds: Leeds Books).

Blaug, Mark (1997) 'Ugly Currents in Modern Economics’, Options Politiques, 18(17), September, pp. 3-8.

Blaug, Mark (1999) 'The Formalist Revolution or What Happened to Orthodox Economics After World War II?', in Backhouse, Roger E. and Creedy, John (eds) (1999) From Classical Economics to the Theory of the Firm: Essays in Honour of D. P. O'Brien (Cheltenham: Edward Elgar), pp. 257-80.

Blaug, Mark (2003) 'The Formalist Revolution of the 1950s', in Samuels, Warren J., Biddle, Jeff E. and Davis, John B. (eds) (2003) A Companion to the History of Economic Thought (Malden, MA and Oxford, UK: Blackwell), pp. 395-410.

Blinder, Alan (1990) 'Discussion’, American Economic Review, 80, May, pp. 445-7.

Boyd, Robert and Richerson, Peter J. (1985) Culture and the Evolutionary Process (Chicago: University of Chicago Press).

Caldwell, Bruce J. (1982) Beyond Positivism: Economic Methodology in the Twentieth Century (London: Allen and Unwin).

Chick, Victoria and Dow, Sheila C. (2001) 'Formalism, Logic and Reality: A Keynesian Analysis’, Cambridge Journal of Economics, 25(6), November, pp. 705-21.

Downward, Paul (2000) 'A Realist Appraisal of Post-Keynesian Pricing Theory', Cambridge Journal of Economics, 24(2), March, pp. 211-24.

Downward, Paul (ed.) (2003) Applied Economics: A Critical Realist Approach (London and New York: Routledge).

Granger, Clive W. J. (2004) 'Critical Realism and Econometrics: An Econometrician's Viewpoint', in Lewis, Paul A. (ed.) (2004) Transforming Economics: Perspectives on the Critical Realist Project (London and New York: Routledge), pp. 96-106.

Harcourt, Geoffrey C. (1972) Some Cambridge Controversies in the Theory of Capital (Cambridge, Cambridge University Press).

Klamer, Arjo and Colander, David (1990) The Making of an Economist (Boulder: Westview Press).

Krueger, Anne O. et al. (1991) 'Report on the Commission on Graduate Education in Economics’, Journal of Economic Literature, 29(3), September, pp. 1035-53.

Lawson, Tony (1997) Economics and Reality (London and New York: Routledge). 
Lawson, Tony (1999) 'Connections and Distinctions: Post Keynesianism and Critical Realism’, Journal of Post Keynesian Economics, 22(1), Fall, pp. 3-14.

Lawson, Tony (2003) Reorienting Economics (London and New York: Routledge).

Lawson, Tony (2004) 'On Heterodox Economics, Themata and the Use of Mathematics in Economics’, Journal of Economic Methodology, 11(3), September, pp. 329-40.

Mäki, Uskali (1992) 'On the Method of Isolation in Economics', Poznan Studies in the Philosophy of the Sciences and the Humanities, 26, pp. 319-54.

Mäki, Uskali (1994) 'Isolation, Idealization and Truth in Economics', Poznan Studies in the Philosophy of the Sciences and the Humanities, 38, pp. 147-68.

Mantel, Rolf R. (1974) 'On the Characterization of Aggregate Excess Demand', Journal of Economic Theory, 12(2), pp. 348-53.

Murray, J. D. (1989) Mathematical Biology (Berlin: Springer).

Nash, Stephen J. (2004) 'On Closure in Economics’, Journal of Economic Methodology, 11(1), March, pp. 75-89.

Quine, Willard van Orman (1951) 'Two Dogmas of Empiricism', Philosophical Review, 60(1), January, pp. 20-43. Reprinted in Quine, Willard van Orman (1953) From a Logical Point of View (Cambridge, MA: Harvard University Press).

Rizvi, S. Abu Turab (1994) 'The Microfoundations Project in General Equilibrium Theory', Cambridge Journal of Economics, 18(4), August, pp. 357-77.

Rowthorn, Robert E. (1999) 'Unemployment, Wage Bargaining and Capital-Labour Substitution', Cambridge Journal of Economics, 23(4), July, pp. 413-25.

Schelling, Thomas C. (1969) 'Models of Segregation', American Evonomic Review, 59(2), pp. 488-93.

Sraffa, Piero (1960) Production of Commodities by Means of Commodities: Prelude to a Critique of Economic Theory (Cambridge: Cambridge University Press).

Sugden, Robert (2000) 'Credible Worlds: The Status of Theoretical Models in Economics', Journal of Economic Methodology, 7(1), March, pp. 1-31.

Ward, Benjamin (1972) What's Wrong With Economics? (London: Macmillan).

Wright, Erik Olin (1994) Interrogating Inequality: Essays on Class Analysis, Socialism and Marxism (London: Verso). 